\title{
Article \\ Pomegranate Peel Extract Is a Potential Alternative Therapeutic for Giardiasis
}

\author{
Asmaa M. El-Kady ${ }^{1}$, Iman A. M. Abdel-Rahman ${ }^{2}{ }^{\circledR}$, Samer S. Fouad ${ }^{3}$, Khaled S. Allemailem ${ }^{4}{ }^{\oplus}$, Taghrid Istivan ${ }^{5}$, \\ Sheren F. M. Ahmed ${ }^{6}\left(\mathbb{D}\right.$, Al Shaimaa Hasan ${ }^{7}$, Heba A. Osman ${ }^{8} \mathbb{D}$ and Hatem A. Elshabrawy ${ }^{9, *}$
}

check for

updates

Citation: El-Kady, A.M.; Abdel-

Rahman, I.A.M.; Fouad, S.S.;

Allemailem, K.S.; Istivan, T.; Ahmed,

S.F.M.; Hasan, A.S.; Osman, H.A.;

Elshabrawy, H.A. Pomegranate Peel

Extract Is a Potential Alternative

Therapeutic for Giardiasis. Antibiotics

2021, 10, 705. https://doi.org/

10.3390/antibiotics 10060705

Academic Editor: Marc Maresca

Received: 6 May 2021

Accepted: 7 June 2021

Published: 11 June 2021

Publisher's Note: MDPI stays neutral with regard to jurisdictional claims in published maps and institutional affiliations.

Copyright: (C) 2021 by the authors. Licensee MDPI, Basel, Switzerland. This article is an open access article distributed under the terms and conditions of the Creative Commons Attribution (CC BY) license (https:/ / creativecommons.org/licenses/by/ $4.0 /)$.
1 Department of Medical Parasitology, Faculty of Medicine, South Valley University, Qena 83523, Egypt; asmaa.elkady@med.svu.edu.eg

2 Department of Pharmacognosy, Faculty of Pharmacy, South Valley University, Qena 83523, Egypt; emanabdelraheem@svu.edu.eg

3 Veterinary Clinical Pathology, Qena University Hospital, South Valley University, Qena 83523, Egypt; samer.saad80@yahoo.com

4 Department of Medical Laboratories, College of Applied Medical Sciences, Qassim University, Buraydah 51452, Saudi Arabia; K.allemailem@qu.edu.sa

5 Biosciences and Food Technology, School of Science, RMIT University, Melbourne, Bundoora, VIC 3083, Australia; Taghrid.istivan@rmit.edu.au

6 Department of Pathology, Faculty of Medicine, Sohag University, Sohag 82524, Egypt; shery.pathology@yahoo.com

7 Department of Medical Pharmacology, Faculty of Medicine, South Valley University, Qena 83523, Egypt; drelshimaa.hassan@med.svu.edu.eg

8 Tropical Medicine, Gastroenterology and Hepatology Department, Faculty of Medicine, South Valley University, Qena 83523, Egypt; hebaahmed198098@yahoo.com

9 Department of Molecular and Cellular Biology, College of Osteopathic Medicine, Sam Houston State University, Conroe, TX 77304, USA

* Correspondence: hatem.elshabrawy@shsu.edu; Tel.: +1-(936)-202-5216; Fax: +1-(936)-202-5260

Abstract: Giardiasis is a major diarrheal disease affecting approximately 2.5 million children annually in developing countries. Several studies have reported the resistance of Giardia lamblia (G. lamblia) to multiple drugs. Therefore, identifying an effective drug for giardiasis is a necessity. This study examined the antiparasitic effect of Punica granatum (pomegranate) and evaluated its therapeutic efficacy in rats infected with G. lamblia. In vitro study showed high efficacy of pomegranate peel ethanolic extract in killing G. lamblia cysts as demonstrated by eosin vital staining. We showed that treating infected rats with pomegranate extract resulted in a marked reduction in the mean number of G. lamblia cysts and trophozoites in feces and intestine respectively. Interestingly, the number of G. lamblia trophozoites and cysts were significantly lower in the pomegranate extract-treated group compared to the metronidazole-positive control group. Moreover, pomegranate extract treatment significantly induced nitric oxide (NO) and reduced serum IL- 6 and TNF- $\alpha$, compared to infected untreated rats. Histological and scanning electron microscopy (SEM) examination of the jejunum and duodenum of pomegranate extract-treated animals confirmed the antiparasitic effect of the extract, and demonstrated the restoration of villi structure with reduction of villi atrophy, decreased infiltration of lymphocytes, and protection of intestinal cells from apoptotic cell death. In conclusion, our data show that the pomegranate peel extract is effective in controlling G. lamblia infections, which suggests that it could be a viable treatment option for giardiasis.

Keywords: pomegranate; Punica granatum; Giardia lamblia; giardiasis; IL-6; NO; TNF- $\alpha$; cysts; trophozoites; intestine; villi; caspase-3

\section{Introduction}

Giardiasis, caused by Giardia lamblia (G. lamblia), has been considered the second-most common cause of infectious diarrhea in humans after viral diarrhea [1]. According to the World Health Organization (WHO), G. lamblia is one of the most common intestinal 
parasites affecting Eastern Mediterranean and African children and is now included in the WHO's Neglected Disease Initiative [2]. It causes approximately 2.5 million cases of childhood diarrhea annually in developing countries [3,4]. Prevalence of giardiasis among children in Egypt increased to $27.3 \%$ [5,6]. G. lamblia is typically transmitted by exposure to contaminated water and food and could remain asymptomatic or become symptomatic with a wide range of clinical symptoms [7-9]. In a natural setting, the rate of symptomatic infection varies from $5 \%$ to $70 \%$. In $70-75 \%$ of symptomatic patients, abdominal cramping, bloating, and flatulence have been reported [5,6]. Other complications of giardiasis include weight loss, malabsorption, and growth retardation [10,11]. In developing countries, giardiasis is a common cause of chronic diarrhea and growth retardation in children [12].

In giardiasis, intestinal colonization by the parasite has been identified to cause microvillus shortening and villous flattening or atrophy [13]. These pathological changes, possibly in combination with other pathological mechanisms, such as reduction in intestinal disaccharidase and protease activity, may be the direct causes of giardia-associated diarrhea. Giardia-induced apoptosis of enterocytes, by activation of caspases, is a key mechanism of the giardiasis-induced enteric pathology [14]. G. lamblia trophozoites have been shown to induce apoptosis in enterocytes both in vitro and in chronic giardiasis patients [15-17]. Giardia-induced apoptosis was reported to be mediated via intrinsic and extrinsic apoptosis pathways. The intrinsic pathway starts by activation of pro-apoptotic proteins such as caspase-3 and -9 , leading to apoptotic cell death $[15,16]$. Moreover, it is well documented that G. lamblia infections trigger the extrinsic apoptotic pathway by activating caspase-8 [16]. In addition, recent studies have established that immune-mediated apoptosis induced by Fas or TNF- $\alpha$ is responsible for increased epithelial permeability in giardiasis [18].

Many drugs, including metronidazole, are currently used in the treatment of human giardiasis. Metronidazole was initially used in treating Trichomonas vaginalis infections [19]. Since then, its therapeutic applications have been extended to include treatment of amoebiasis, giardiasis, and anaerobic bacterial infections [20-22]. However, a number of side effects have been reported following metronidazole treatment, including headache, vertigo, nausea, and a metallic taste in the mouth $[23,24]$. In addition, pancreatitis, neurotoxicity, and neutropenia have been attributed to nitroimidazole anti-infectives, including metronidazole [21,23]. Metronidazole has been identified to be mutagenic in bacteria and carcinogenic in mice and rats at high doses over longer periods $[25,26]$. Clinical studies have reported the resistance of G. lamblia to different medications $[19,22]$. For that reason, studies have focused on testing the efficacy of herbal drugs in treating giardiasis [27].

Pomegranate (Punica granatum) is a plant that has been used in folk medicine for the treatment of various human diseases [28]. The constituents of pomegranate include high levels of hydrolyzable tannins (punicalins and punicalagins), ellagic acid (a component of ellagitannins), and gallic acid (a component of gallotannins), with well-known antioxidant and antimicrobial activities [29]. Additionally, pomegranate is widespread in the Mediterranean region and is well known for its anti-inflammatory effect due to its high content of antioxidants [28]. Furthermore, pomegranate is a potential antifungal and it is casually used in the treatment of Trichophyton rubrum [30]. Pomegranate exhibits several other pharmacological activities, including anthelmintic effects on various intestinal trematodes, nematodes, and cestodes in addition to its anti-amoebic, antimalarial, and anticoccidial effects [31-37].

In this study, we aimed to investigate the therapeutic utility of pomegranate in G. lamblia infections. For that purpose, pomegranate peel ethanolic extract was tested for its effectiveness in eliminating the parasite and ameliorating the disease in a rat model of giardiasis.

\section{Materials and Methods}

\subsection{Plant Material}

Fresh Egyptian pomegranate fruits were collected from an agricultural field near South Valley University. The taxonomic identification and authentication of the collected plants were conducted by the Department of Pharmacognosy, Faculty of Pharmacy, South 
Valley University, Egypt. A voucher specimen of the plant (code: Pg.90) was kept in the herbarium, Department of Pharmacognosy, Faculty of Pharmacy, South Valley University, Egypt. The pomegranates were thoroughly washed to get rid of any debris; the peels were removed, cut into small pieces, and dried in an air circulatory tray drier at $60^{\circ} \mathrm{C}$ for $6 \mathrm{~h}$. Dried peels were ground using a laboratory disc mill and the powder was passed through a 20 mesh sieve. The powder was stored at room temperature until used for extraction.

\subsection{Preparation of Pomegranate Extract}

Pomegranate ethanolic extract was prepared as previously described by Almoniem et al. [28]. Briefly, dried pomegranate peels were powdered. The ethanolic extract was prepared by maceration of $150 \mathrm{~g}$ of peels powder in $750 \mathrm{~mL}$ of $70 \%$ ethanol for $16 \mathrm{~h}$ at room temperature, and then filtered. Filtrate was evaporated to dryness in a rotary evaporator under reduced pressure, to obtain the crude ethanolic extract. The dry crude extract residue $(11 \mathrm{~g})$ was stored at $4{ }^{\circ} \mathrm{C}$ for subsequent preparation of the required doses.

\subsection{Collection of Cysts}

G. lamblia cysts were obtained from stools of patients who complained of diarrhea and presented to outpatient clinics of the University Hospital at South Valley University, Qena, Egypt. Positive samples were processed, washed with saline, centrifuged, and viability of cysts was confirmed using $0.1 \%$ eosin vital staining. We then counted the number of cysts in phosphate-buffered saline (PBS). The process was repeated until we finally obtained a concentration of $10,000 \mathrm{cysts} / \mathrm{mL}$ of PBS, which is the required dose for the animal infection experiments.

\subsection{In Vitro Test of the Effect of Pomegranate Ethanolic Extract on G. lamblia Cysts}

We added $2 \mathrm{~mL}$ of different concentrations $(1,10$ and $50 \mathrm{mg} / \mathrm{mL})$ of pomegranate ethanolic extract to $1 \mathrm{~mL}$ of G. lamblia cysts suspension in sterile test tubes. We used $2 \mathrm{~mL}$ of metronidazole at a concentration of $50 \mu \mathrm{g} / \mathrm{mL}$ as the positive control [38], whereas the untreated G. lamblia cyst suspension was used as the negative control. All test tubes were thoroughly mixed, incubated at $37^{\circ} \mathrm{C}$ for $5,10,30$ or $60 \mathrm{~min}$. At the end of each time interval, G. lamblia cysts viability was assessed using $0.1 \%$ eosin vital staining and a hemocytometer at $400 \times$ magnification. The percentage of dead cysts/high-power field (HPF) was calculated according to Al-kaissi [39].

\subsection{Animal Experiments}

Animal experiments were performed in the Animal Facility at the Parasitology Department, Faculty of Medicine, South Valley University, Qena, Egypt. Thirty-two 3-4-week-old male golden rats, weighing 150-200 g, were used for the present study. Animals were initially examined daily for the presence of any parasitic infections. To establish the G. lamblia infection, 10,000 cysts were administered to animals [40]. In our study, animals were divided equally into four groups with eight rats in each group. The first group represents the uninfected and untreated control group, whereas the second group included animals that were infected with G. lamblia but did not receive any treatment (negative control). The third and fourth animal groups consisted of infected animals that were treated for 7 days with either ethanolic extract of pomegranate at a dose of $300 \mathrm{mg} / \mathrm{kg} /$ day or metronidazole (positive control) at a dose of $15 \mathrm{mg} / \mathrm{kg} /$ day, respectively [32,41]. Treatments started on the third day post-infection and all animals were sacrificed 3 days after the end of treatments [41].

\subsection{Assessment of the In Vivo Efficacy of the Extract}

\subsubsection{Determination of Cysts and Trophozoite Counts}

To ensure infection of animals, fecal samples were examined microscopically for the presence of cysts on the third day post-infection. Three days after the end of treatments, the number of cysts were counted in stools of all animals/high-power field [42]. Briefly, $1 \mathrm{~g}$ 
of freshly collected feces from each rat was completely homogenized in $10 \mathrm{~mL}$ of formal saline, then cysts were counted using hemocytometer at $400 \times$ magnification, as previously described [42]. After sacrificing the animals, the mean number of G. lamblia trophozoites in the intestine was determined based on five different high-power fields $(400 \times)$ /animal, as previously described [43].

\subsubsection{Quantification of Proinflammatory Cytokines and NO}

Sera were prepared from blood samples and stored at $-20{ }^{\circ} \mathrm{C}$ for analysis. We quantified the levels of IL- 6 and TNF- $\alpha$ in animals' sera using the IL- 6 and TNF- $\alpha$ ELISA Kits, according to the manufacturer's instructions (KOMA BIOTECH INC., Seoul, South Korea, Cat. No. K0331229 and Cat. No. K0331196, respectively) [44]. The NO levels were determined by measuring $\mathrm{NO}$ end products (NOx) using Biodiagnostic colorimetric assay kit.

\subsubsection{Histological Studies}

Hematoxylin and Eosin Staining

Formalin-fixed paraffin-embedded intestinal tissue blocks were used to prepare 4 - $\mu \mathrm{m}$-thick sections. These sections were deparaffinized in xylene, rehydrated in decreasing alcohol concentrations (100\%, 80\%, 70\%, and 50\%; $1 \mathrm{~min}$ each), and rinsed in distilled water followed by running tap water for 3-5 min. The slides were stained with hematoxylin for 5-7 min, washed in running tap water, and then stained with eosin for 3-5 min followed by running tap water. The slides were dehydrated in increasing concentrations of ethanol (50\% ethanol, 70\%, 80\%, and 100\%; 1 min each), cleared in xylene, and mounted with dibutyl phthalate polystyrene xylene (DPX) and cover-slipped. Slides were then examined using light microscopy, at $400 \times$ magnification, to evaluate intestinal villi atrophy and lymphocyte infiltration in different animal groups. We recorded the number of animals/group with either absent, mild, moderate, or marked villi atrophy. Similarly, we counted the number of animals / group with mild, moderate, or severe intestinal tissue lymphocyte infiltration.

Immunohistochemistry

Four- $\mu$ m-thick sections were cut and mounted on saline-coated glass slides, which were subsequently incubated overnight at room temperature to optimize adhesion of the tissues onto the slides. The slides were deparaffinized in xylene for $20 \mathrm{~min}$, rehydrated in decreasing concentrations of alcohol (100\% for $5 \mathrm{~min}$, then $2 \mathrm{~min}$ in each of $80 \%, 70 \%$, and $50 \%$ ), and rinsed in distilled water. Endogenous peroxidase activity was blocked by incubating the tissue sections in $0.6 \%$ hydrogen peroxide $\left(\mathrm{H}_{2} \mathrm{O}_{2}\right)$ for $10 \mathrm{~min}$. The tissue sections were then washed twice with PBS, and antigens were retrieved by boiling the sections twice in Tris/EDTA buffer $(\mathrm{pH}=9.0)$ in a microwave oven at mid-high power for $10 \mathrm{~min}$. Next, sections were left to cool down to room temperature for $30 \mathrm{~min}$. After washing twice with PBS, tissue sections were treated with superblock. Tissue sections were then rinsed twice with PBS and incubated with rabbit recombinant monoclonal Caspase3p12 antibody (clone No. EPR16888, Abcam, Cambridge, MA, USA) at a concentration of 1:2000 overnight at room temperature. Excess reagent was discarded, tissue sections were rinsed twice in PBS containing 0.05\% Tween-20 (PBS-T), then incubated with HRPconjugated goat anti-rabbit secondary antibody (Vivantis Technologies, Selangor Darul Ehsan, Malaysia) at a dilution of 1:5000 for $1 \mathrm{~h}$ at $4^{\circ} \mathrm{C}$. After washing twice with PBS-T, the color was developed by incubating sections with $0.05 \%$ diaminobenzidine (DAB) and $0.01 \% \mathrm{H}_{2} \mathrm{O}_{2}$ for $3 \mathrm{~min}$. Finally, the sections were counterstained with hematoxylin, washed in running water, dehydrated in graded ascending series of alcohols $(70 \%, 80 \%, 90 \%$, and $100 \%$ ), cleared in xylene for 5 min, and mounted with DPX, cover-slipped, and imaged at $400 \times$ magnification. 
Immunohistochemical Scoring

The estimated average staining intensity of caspase- 3 in intestinal tissues was scored as follows: 0 (no signal), 1 (weak signal), 2 (moderate signal) and 3 (strong signal). The percentage of stained cells at each intensity level was graded as $0(<5 \%), 1(5-25 \%), 2(26-50 \%)$, $3(51-75 \%)$, or $4(>75 \%)$. The intensity score and percentage of positive cells were then added to yield the final scores (0-7). A score of 0 indicated absence of caspase-3, scores $\leq 4$ were considered low expression, whereas scores $>4$ reflected high expression [45].

\subsubsection{Scanning and Transmission Electron Microscopy (SEM)}

Tissues from the duodenum and proximal jejunum of the sacrificed rats were immediately fixed in 3\% cold glutaraldehyde in phosphate-buffered saline (PBS, pH 7.4) for $2 \mathrm{~h}$. The tissues were then washed $3 \times$ with PBS for 10 min each. Next, they were fixed in $2 \%$ osmium tetroxide in water for $2 \mathrm{~h}$, rinsed $3 \times$ in water for $5 \mathrm{~min}$ each, then dehydrated in ascending ethanol concentrations (once for $10 \mathrm{~min}$ in 30\%,50\%,70\%, 80\%, 90\% ethanol, and twice in 100\% ethanol). The tissues were then dried using critical-point drying, with liquid $\mathrm{CO}_{2}$, at $34^{\circ} \mathrm{C}$ and pressure of 1200 psi. Finally, tissues were mounted on stainless steel holders, sputter-coated with a thin layer of gold, and imaged by scanning electron microscope (JEOL JSM-5500 LV, JEOL, Tokyo, Japan). SEM examination was carried out in the electron microscopy unit, South Valley University, Qena, Egypt, according to Hayat1981 [46].

\subsection{Statistical Analysis}

The collected data were analyzed using the Statistical Package for the Social Sciences (SPSS) version 20 for Windows. All values were expressed as means and error bars represent standard deviations. Differences between groups were determined using analysis of variance tests (ANOVA). Chi-square test was used to determine significance when comparing number of animals in different groups with villi atrophy, lymphocyte infiltration, and caspase- 3 . In all experiments, probability $(p)$ values $<0.05$ were considered statistically significant.

\section{Results}

\subsection{Pomegranate Extract Effectively Killed G. lamblia Cysts}

We show that incubation of Giardia cysts with different concentrations of pomegranate extract resulted in a significant increase in the percentage of dead Giardia cysts, which was dose- and time-dependent $(p<0.001)$. The highest percentage of dead cysts $(98 \%)$ was seen after $60 \mathrm{~min}$ incubation with $50 \mathrm{mg} / \mathrm{mL}$ of pomegranate extract (Table 1 and Figure 1).

Table 1. The effect of increasing concentrations of pomegranate extract on G. lamblia cysts' viability at different exposure times compared to metronidazole $(50 \mu \mathrm{g} / \mathrm{mL})$. Each treatment was performed in triplicate and asterisks $\left(^{*}\right)$ indicate a significant increase in percentage of dead cysts compared to untreated control $(p<0.001)$.

\begin{tabular}{|c|c|c|c|c|c|}
\hline \multirow{2}{*}{ Exposure Time } & \multicolumn{3}{|c|}{ Pomegranate Extract } & \multirow{2}{*}{$\begin{array}{c}\text { Metronidazole } \\
50 \mu \mathrm{g} / \mathrm{mL}\end{array}$} & \multirow{2}{*}{ Control } \\
\hline & $1 \mathrm{mg} / \mathrm{mL}$ & $10 \mathrm{mg} / \mathrm{mL}$ & $50 \mathrm{mg} / \mathrm{mL}$ & & \\
\hline $5 \mathrm{~min}$ & $51 \pm 2.7$ * & $53 \pm 2.1^{*}$ & $59 \pm 1.6^{*}$ & $59 \pm 0.7^{*}$ & $2 \pm 0.2$ \\
\hline $10 \mathrm{~min}$ & $63 \pm 1.9$ * & $64 \pm 2.1 *$ & $71 \pm 1.3^{*}$ & $60 \pm 1.3 *$ & $2 \pm 0.4$ \\
\hline $30 \mathrm{~min}$ & $71 \pm 2.4^{*}$ & $75 \pm 2.6^{*}$ & $77 \pm 1.7^{*}$ & $77 \pm 1.5^{*}$ & $4 \pm 1.4$ \\
\hline $60 \mathrm{~min}$ & $84 \pm 3.4$ * & $88 \pm 3.1^{*}$ & $98 \pm 1.2 *$ & $91 \pm 2.3$ * & $6 \pm 1.8$ \\
\hline
\end{tabular}



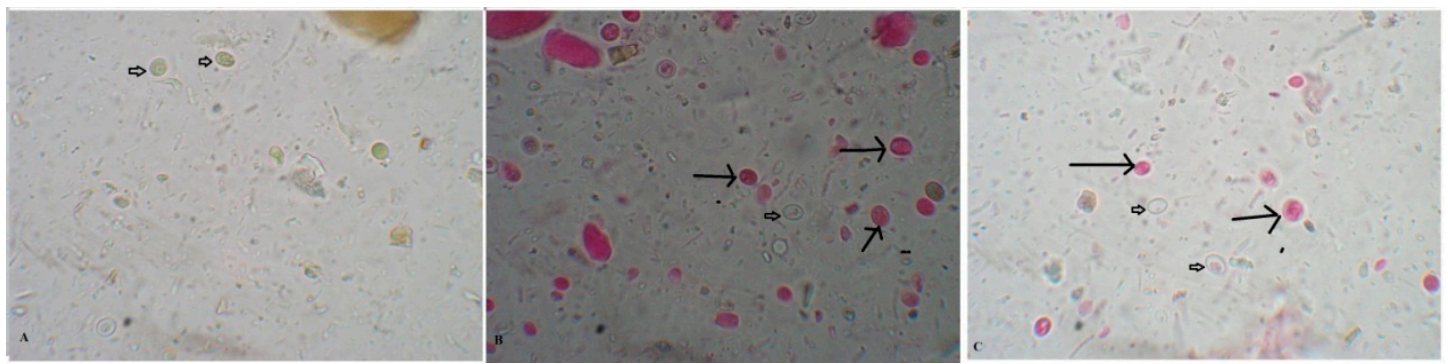

Figure 1. Pomegranate extract killed G. lamblia cysts. (A) Untreated viable G. lamblia unstained cysts after staining with $0.1 \%$ eosin vital stain (Negative control). Dead cysts (long arrows) and living cysts (short arrows) are shown after incubation with pomegranate extract $(50 \mathrm{mg} / \mathrm{mL})(\mathbf{B})$ and metronidazole $(50 \mu \mathrm{g} / \mathrm{mL})(\mathbf{C})$ for $30 \mathrm{~min}(400 \times$ magnification).

\subsection{Pomegranate Extract Reduced Cysts and Trophozoite Counts in G. lamblia-Infected Animals}

Examination of fecal samples from pomegranate extract- or metronidazole-treated animals revealed a statistically significant reduction in the number of G. lamblia cysts compared to infected untreated rats $(p=0.003$; Figure 2). Similarly, we found a significant reduction in the number of G. lamblia trophozoites in the intestines of pomegranate extract and metronidazole-treated rats compared to the infected untreated rats $(p=0.001$; Figure 2). Interestingly, the number of cysts and trophozoites in pomegranate extract-treated animals were significantly lower than those in the metronidazole-treated group $(p=0.001)$.

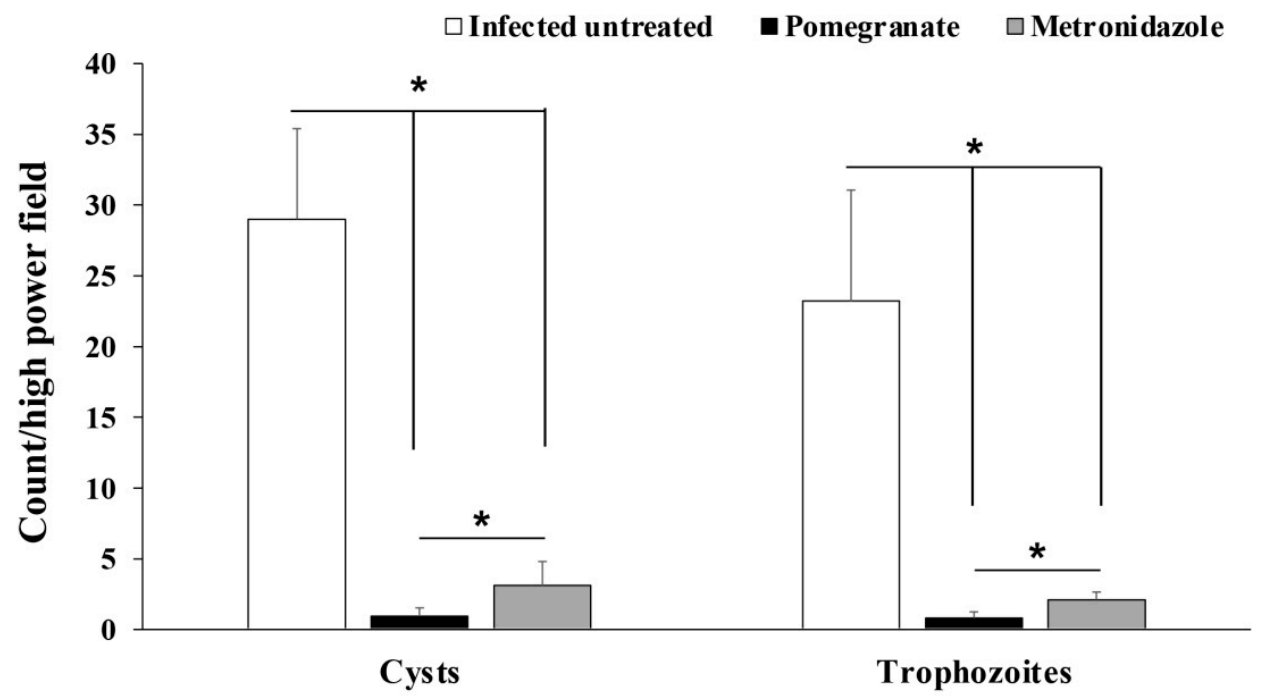

Figure 2. Effect of pomegranate extract or metronidazole treatments on the number of G. lamblia cysts and trophozoites in stool and intestine respectively. Data are expressed as means with error bars representing SD $(n=8)$ and were analyzed using ANOVA. Asterisks $\left({ }^{*}\right)$ indicate a significant difference in the numbers of cysts or trophozoites in treated groups compared to the infected untreated group ( $p=0.003$ and 0.001 for cysts and trophozoites, respectively), and a significant difference between the metronidazole- and pomegranate-treated groups; $p=0.001$.

3.3. Treatment with Pomegranate Extract Reduced the Levels of Proinflammatory Cytokines and Increased NO Production in G. lamblia-Infected Animals

Next, we aimed to investigate the effect of pomegranate extract on inflammation by measuring the serum levels of proinflammatory cytokines such as IL- 6 and TNF- $\alpha$. Our results showed that animals infected with G. lamblia had significantly higher serum levels of IL- 6 and TNF- $\alpha$, which were significantly reduced by pomegranate and metronidazole treatments (Figure 3A; $p<0.005$ ).

We also detected higher levels of serum NO end products (NOx), indicative of higher NO production, in pomegranate extract- and metronidazole-treated rats compared to infected untreated rats (Figure 3B; $p<0.005$ ). 
A

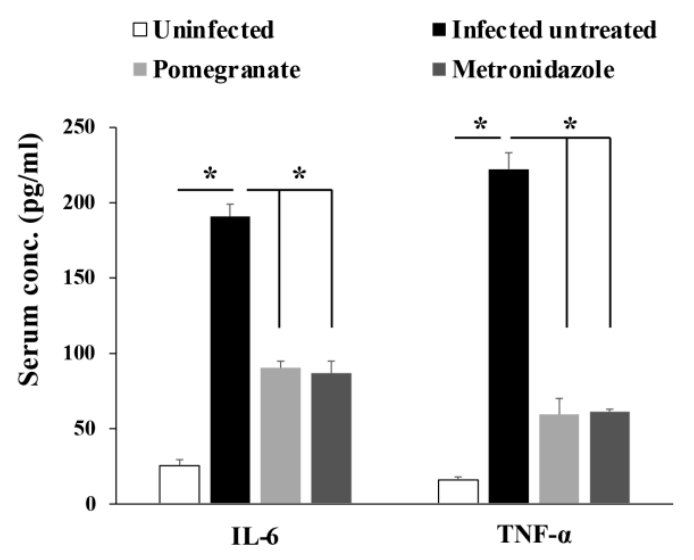

B

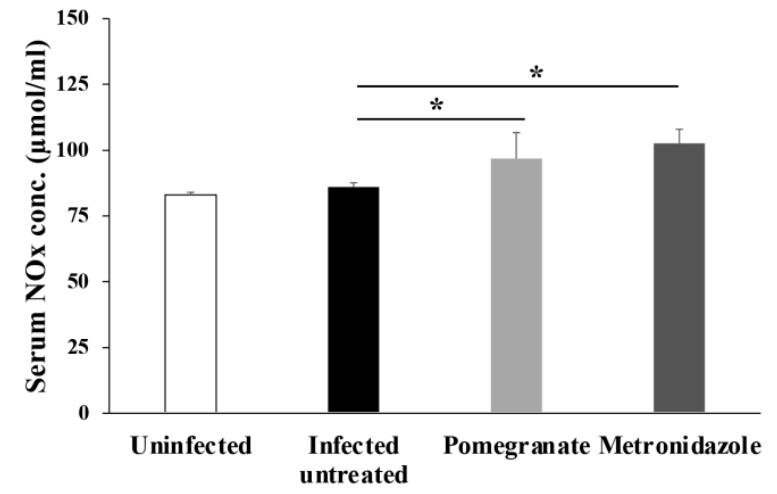

Figure 3. Pomegranate extract reduced levels of IL-6, TNF- $\alpha$ and increased NO production in animals infected with G. lamblia. Serum levels of IL-6 and TNF- $\alpha($ A) or NOx (B) were quantified in different animal groups. Data are expressed as means with error bars representing SD $(n=8)$, and were analyzed using ANOVA. Asterisks $\left(^{*}\right)$ indicate a significant difference $(p<0.005)$.

\subsection{Treatment with Pomegranate Extract Reduced Lymphocyte Infiltration and Protected the Intestinal Villi from Infection-Induced Pathology}

Histological examination of the small intestine of the uninfected untreated animals showed normal intestinal histology, whereas variable degrees of villi atrophy (mostly moderate-to-marked atrophy) were seen in significant numbers of infected untreated animals (Figure 4A,B, and Table 2; $p=0.001$ ). Treatment with metronidazole resulted in a significant reduction in villi atrophy (absent to mild) (Figure $4 \mathrm{C}$ and Table $2 ; p=0.001$ ). Similarly, pomegranate treatment significantly restored villi structure with $50 \%$ of animals with no atrophy, 25\% with mild atrophy, and 25\% with moderate atrophy (Figure 4D and Table 2; $p=0.001$ ). Additionally, variable degrees of lymphocyte infiltration were observed in the lamina propria of infected untreated animals with the majority $(62.5 \%)$ showing marked lymphocyte infiltration compared to uninfected animals (Figure 4A,B, and Table 3; $p=0.005$ ). However, both metronidazole and pomegranate treatments significantly reduced the lymphocyte infiltration into lamina propria (75\% of animals showed mild lymphocyte infiltration) (Figure $4 \mathrm{C}, \mathrm{D}$, and Table $3 ; p=0.005$ ). All the previous results imply that pomegranate treatment is effective in restoring villi and reducing inflammation caused by G. lamblia infection.

Table 2. Therapeutic effect of pomegranate extract on intestinal villi atrophy caused by G. lamblia infection. Numbers of rats with absent villi atrophy, mild, moderate, or marked atrophy are presented in addition to their percentages of the total number of rats in each group (8 rats/group). Pomegranate, similar to metronidazole (positive control), significantly reduced villi atrophy compared to infected untreated animals; $p=0.001$.

\begin{tabular}{|c|c|c|c|c|c|}
\hline \multirow{2}{*}{ Animal Group } & \multicolumn{4}{|c|}{ Atrophy of Intestinal Villi } & \multirow{2}{*}{$p$-Value } \\
\hline & Absent & Mild & Moderate & Marked & \\
\hline Uninfected untreated & $8(100 \%)$ & $0(0 \%)$ & $0(0 \%)$ & $0(0 \%)$ & \multirow{4}{*}{0.001} \\
\hline Infected untreated & $0(0 \%)$ & $1(12.5 \%)$ & $3(37.5 \%)$ & $4(50 \%)$ & \\
\hline Pomegranate treatment & $4(50 \%)$ & $2(25 \%)$ & $2(25 \%)$ & $0(0 \%)$ & \\
\hline Metronidazole treatment & $5(62.5 \%)$ & $3(37.5 \%)$ & $0(0 \%)$ & $0(0 \%)$ & \\
\hline
\end{tabular}


Table 3. Treatment with pomegranate extract reduced lymphocyte infiltration into intestinal tissue of G. lamblia-infected rats. Number of animals with mild, moderate, or marked lymphocyte infiltration are shown including their percentages of total number of animals/group $(n=8)$. Pomegranate, similar to metronidazole (positive control), significantly reduced lymphocyte infiltration compared to infected untreated animals; $p=0.005$.

\begin{tabular}{ccccc}
\hline Animal Group & Mild & $\begin{array}{c}\text { Lymphocytic Infiltration } \\
\text { Moderate }\end{array}$ & Marked & \multirow{2}{*}{-Value } \\
\hline Uninfected untreated & $6(75 \%)$ & $2(25 \%)$ & $0(0 \%)$ & \\
Infected untreated & $0(0 \%)$ & $3(37.5 \%)$ & $5(62.5 \%)$ & 0.005 \\
Pomegranate treatment & $6(75 \%)$ & $1(12.5 \%)$ & $1(12.5 \%)$ & \\
Metronidazole treatment & $6(75 \%)$ & $2(25 \%)$ & $0(0 \%)$ & \\
\hline
\end{tabular}
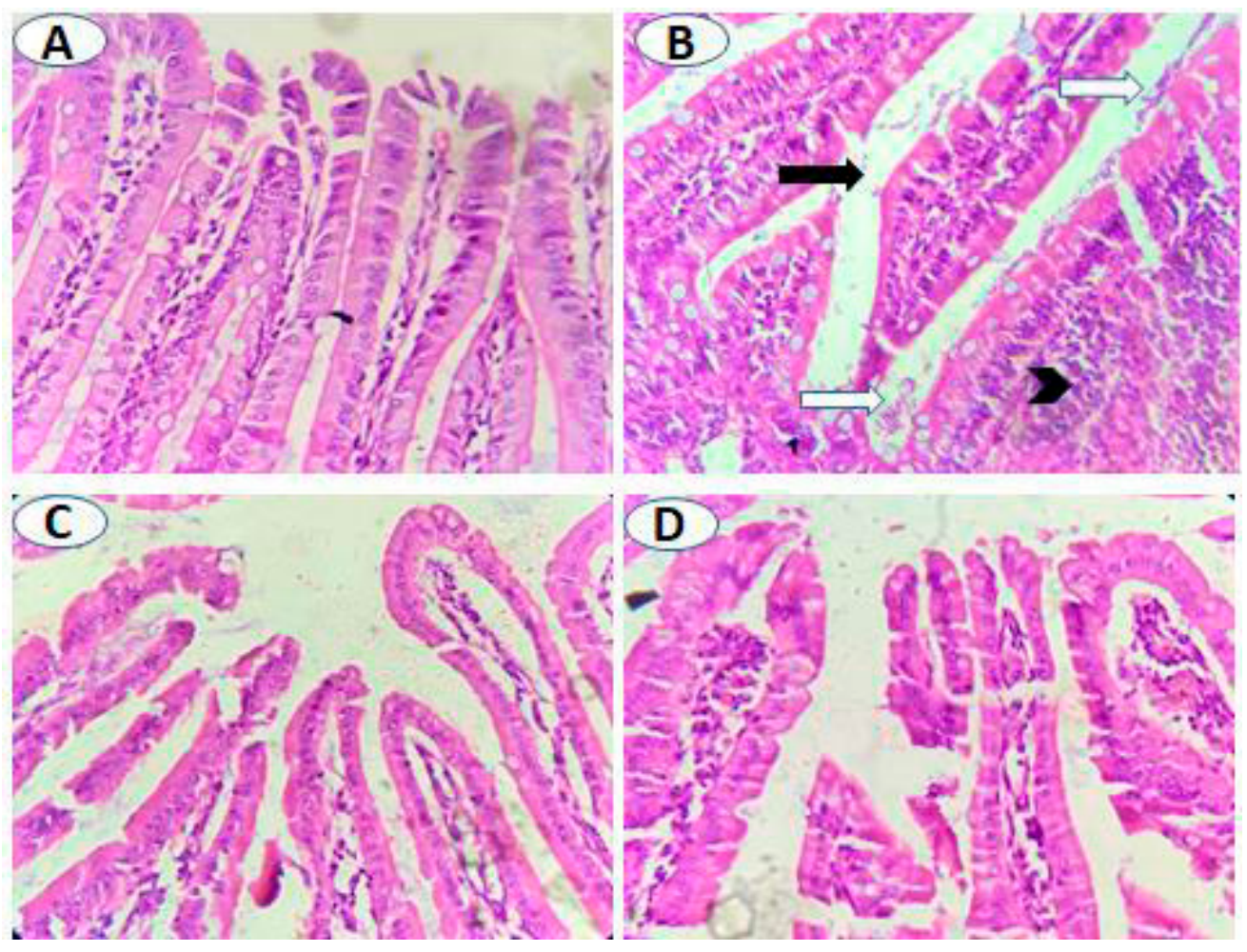

Figure 4. Pomegranate extract treatment protected intestinal villi from G. lamblia-induced atrophy. (A) Normally appearing villi in uninfected animals. (B) Villi of infected untreated animals showing atrophy (black arrow), marked infiltration of inflammatory cells mainly lymphocytes in lamina propria (black arrowhead) and numerous flagellated G. lamblia (white arrows). Nearly normally appearing intestinal villi with reduced lymphocyte infiltration and absence of G. lamblia trophozoites in both metronidazole- (C) and pomegranate-treated animals (D). Magnification is $400 \times$.

\subsection{Pomegranate Extract Treatment Protected Intestinal Tissue from Apoptotic Cell Death Following G. lamblia Infection}

Immunohistochemical staining of caspase- 3 in intestinal tissues of animals from different groups showed absence of caspase-3 in 50\% of uninfected animals, whereas intestines of a significantly higher number of infected untreated animals (62.5\%) demonstrated high levels of capsase-3 (Figure 5A,B, and Table 4). Interestingly, pomegranate- and metronidazoletreated animals showed variable levels of caspase- 3 with a significantly higher number of animals having low levels (62.5\%) (Figure 5C,D, and Table $4 ; p=0.001)$. These results indicate that pomegranate extract treatment is effective in preventing apoptotic cell death of intestinal cells that is induced by G. lamblia infection. 

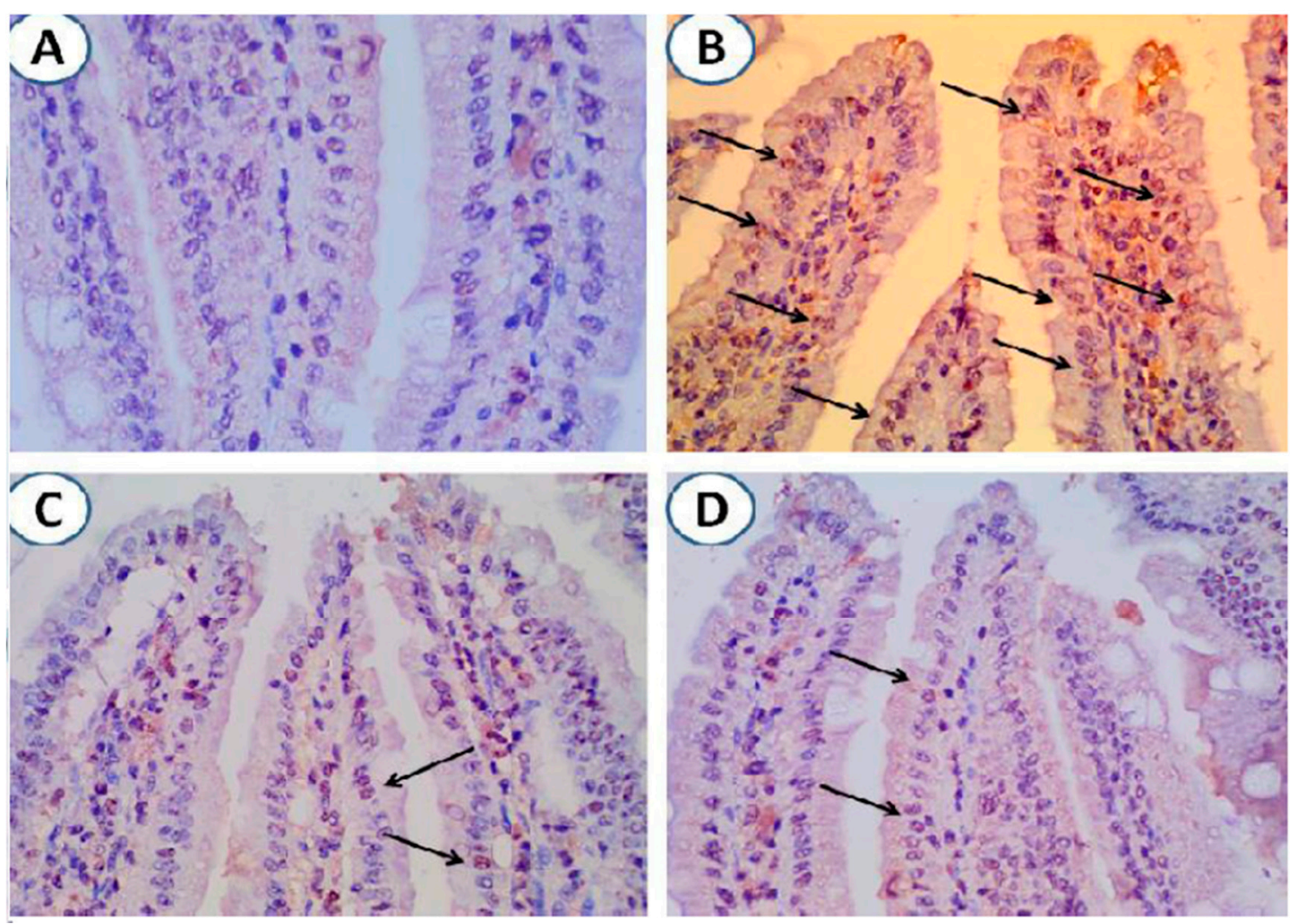

Figure 5. Treatment with pomegranate-protected intestinal cells from infection-induced apoptosis. (A) Intestinal tissue from uninfected animals with no expression of caspase-3. (B) Intestinal tissue from G. lamblia-infected untreated animals showing marked expression of caspase-3 (arrows). (C) and (D). Minimal expression of caspase-3 in intestinal tissues of infected animals treated with pomegranate extract or metronidazole respectively (arrows). Magnification is $400 \times$.

Table 4. Treatment with pomegranate extract reduced caspase-3 in intestinal tissue of G. lambliainfected rats. Number of animals with negative, low, or high levels of caspase- 3 are shown including their percentages of total number of animals/group $(n=8)$. Pomegranate, similar to metronidazole (positive control), significantly increased the number of animals with low levels of caspase-3, and reduced the number of animals with high levels of caspase- 3 compared to infected untreated animals; $p=0.001$.

\begin{tabular}{ccccc}
\hline Animal Group & Negative & $\begin{array}{c}\text { Caspase-3 Levels } \\
\text { Low }\end{array}$ & High & $p$-Value \\
\hline Uninfected untreated & $4(50 \%)$ & $3(37.5 \%)$ & $1(12.5 \%)$ & \\
Infected untreated & $1(12.5 \%)$ & $2(25 \%)$ & $5(62.5 \%)$ & 0.001 \\
Pomegranate treatment & $2(25 \%)$ & $5(62.5 \%)$ & $1(12.5 \%)$ & \\
Metronidazole treatment & $1(12.5 \%)$ & $5(62.5 \%)$ & $2(25 \%)$ & \\
\hline
\end{tabular}

3.6. Scanning Electron Microscopy (SEM) Showed Marked Ability of Pomegranate Extract to Kill G. lamblia Trophozoites and Protect Intestinal Tissue from G. lamblia Infection

Our SEM of the proximal part of the small intestine showed high efficacy of pomegranate extract in damaging G. lamblia trophozoites and restoring the structure of intestinal villi. Figure 6A,B shows normal mucosa from uninfected rats with no trophozoites. Examination of intestine from infected untreated animals showed damaged eroded mucosa and harbored G. lamblia trophozoites with normal morphology (normal ventral disc, flagella, and attachment to the damaged and eroded intestinal mucosa) (Figure 6C,D). However, SEM images of small intestine from animals that were treated with metronidazole (Figure 6E,F) or pomegranate peel extract (Figure 6G,H) showed recovered intestinal mucosa, and G. lamblia trophozoites with distorted morphology (loss of flagella, distortion of sucking disc, and loss of attachment to the intestinal mucosa). These results further 
confirm the efficacy of pomegranate extract in killing G. lamblia trophozoites and protecting intestinal tissue of infected rats.

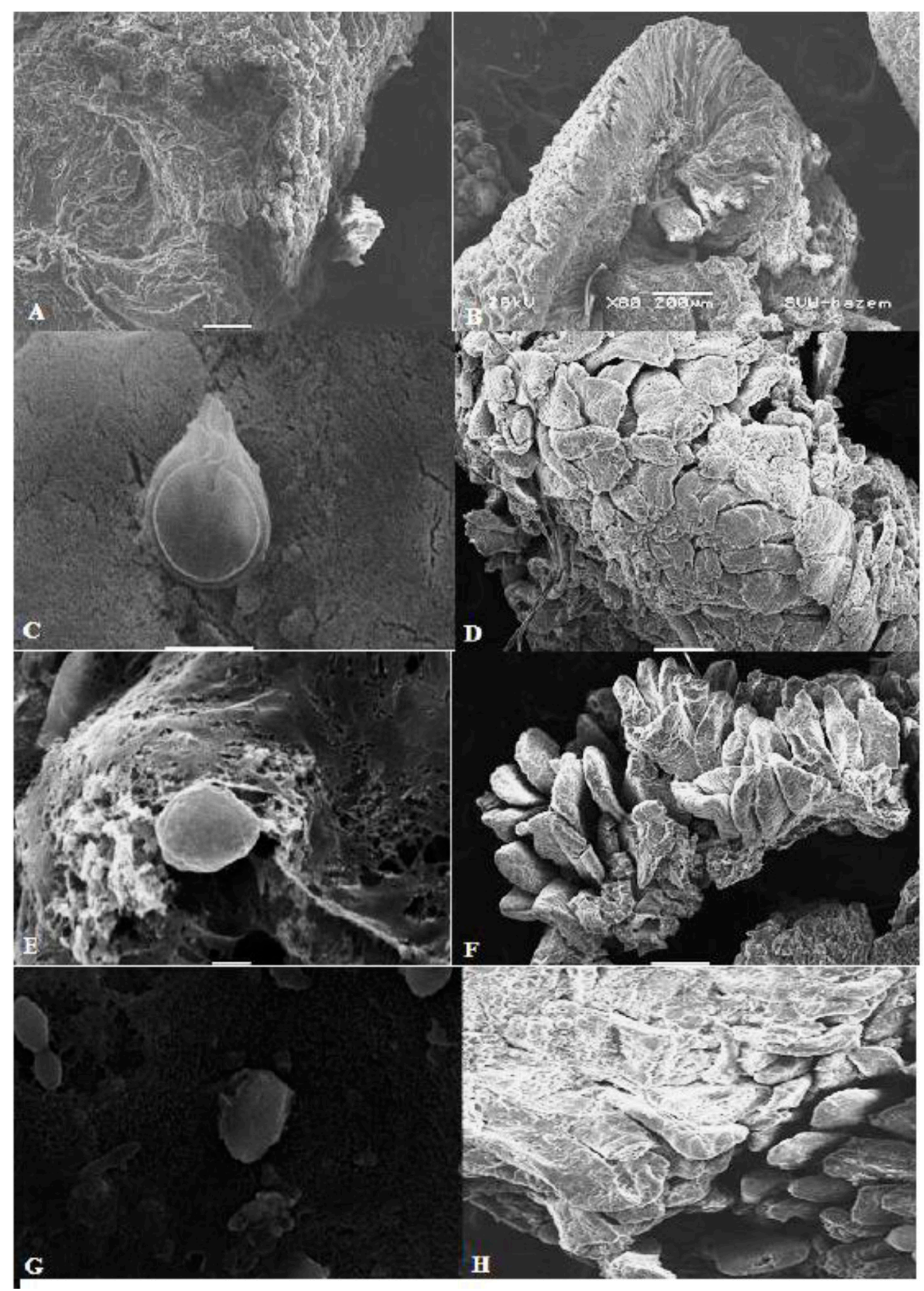

Figure 6. Scanning electron microscopy (SEM) of the intestine of animals from different groups. $(\mathbf{A}, \mathbf{B})$ Normal intestinal mucosa of uninfected rats. (C) SEM of intestine of infected untreated animal showing normal morphology of G. lamblia trophozoite with normal disc and flagella and attachment to the mucosa. (D) SEM image showing damage and erosion of the intestinal mucosa in infected untreated animal. (E) SEM image of intestinal tissue of metronidazole-treated animal showing distorted morphology of G. lamblia trophozoite (loss of flagella and distortion of sucking disc). (F) Recovery of the intestinal mucosa after metronidazole treatment. (G) SEM image of intestinal tissue of pomegranate-treated animal showing distorted morphology of G. lamblia trophozoite (loss of flagella and distortion of sucking disc). (H) SEM image showing marked recovery of the intestinal mucosa after pomegranate extract treatment. 


\section{Discussion}

Giardiasis has become a major global health problem due to resistance of the parasite to currently available drugs. In the current study, we sought to determine the efficacy of pomegranate ethanolic extract in G. lamblia infections. Recently, the use of plants and plant-derived products in treatment of different diseases has gained much attention due to their antimicrobial activities and fewer side effects. Also, these herbal products are particularly useful in cases of resistance to conventional medications. Among these plants, pomegranate has been used in folk medicine and is known to possess antiparasitic, antibacterial, antifungal, and antiviral activities [31-37]. It is well documented that the pomegranate peels contain various active ingredients including tannins, flavonoids, alkaloids and organic acids. Gallagyldilacton, gallic acid, and granatin B were shown to have anti-inflammatory activities [47-49]. In addition, studies have demonstrated that Tannins, such as punicalin, punicalagin, pedunculagin, gallic acid and casuarinin, are potent antioxidants [47,49]. Moreover, flavonoids in pomegranate peels have antibacterial, antiviral, antioxidant, anti-inflammatory and anti-neoplastic activities [50,51].

In our current study, we assessed the therapeutic utility of pomegranate as an antigiardiasis agent. We showed that the pomegranate extract is effective in killing G. lamblia cysts, which is in agreement with previous studies [31-36]. Examination of intestinal mucosa and feces revealed that treatment with pomegranate peel extract markedly reduced the number of trophozoites and cysts in intestinal mucosal and feces of infected animals, respectively, which is consistent with the results of earlier studies [31-36]. Moreover, pomegranate peel extract more effectively reduced trophozoites and cysts than the positive control; metronidazole.

Elimination of trophozoites and fecal cysts in response to pomegranate peel extract treatment, in the present study, may be attributed to the production of NO by activated macrophages, which is cytotoxic through a number of different mechanisms $[35,52,53]$. This mechanism is supported by the higher levels of NO in infected animals that are treated with pomegranate peel extract compared to untreated ones. The lower levels of NO in infected untreated animals have been previously observed by others and could be explained by the ability of the parasite to compete with the host for arginine (substrate for NO) or increase host production of arginase, which reduces arginine availability [54,55]. These mechanisms of limiting NO production are important for trophozoite survival within the intestine [56]. Interestingly, we found that metronidazole-treated rats have slightly higher levels of NO than pomegranate extract-treated animals, which makes pomegranate extract more suitable in the treatment of giardiasis since $\mathrm{NO}$ is cytotoxic, not only for the invading parasites, but also for the host cells $[57,58]$.

Our measurement of IL- 6 and TNF- $\alpha$ serum levels showed higher levels in infected untreated animals compared to uninfected ones, which is in line with studies which demonstrated major roles of these cytokines in controlling giardiasis [59]. However, treatment with pomegranate peel extract or metronidazole significantly lowered the cytokine levels, as shown in other studies [60,61]. Li et al. reported that higher levels of IL-6 triggered the production of TNF- $\alpha$ during G. lamblia infections in mice, and accordingly, TNF- $\alpha$ mRNA levels were lower in IL-6-deficient mice following Giardia infection than in wildtype mice [52]. IL-6 has been shown to stimulate B-cell differentiation, antibody production, and T-cell proliferation and modulate IgA response. Therefore, it is not surprising that IL-6deficient mice exhibit a significant defect in the early control of G. lamblia infection [59,62]. Studies have also shown that mice treated with neutralizing anti-TNF- $\alpha$ antibodies or that are genetically deficient in TNF- $\alpha$ failed to control G. lamblia infection [44]. We show that rats treated with pomegranate peel extract still have higher levels of IL-6 than uninfected rats, which implies that this extract could be beneficial given that IL-6 plays an important role in intestinal epithelial cell repair [63]. Moreover, TNF- $\alpha$ levels were significantly lower in the pomegranate extract-treated group than in infected untreated group, which is also advantageous since high levels of TNF- $\alpha$ may result in intestinal cell damage [64]. 
Our histopathological analysis showed that intestines of infected untreated animals exhibit higher numbers of G. lamblia trophozoites, marked villi atrophy, and significant lymphocyte infiltration, all of which are consistent with many other studies [41,65]. Damage to the intestinal mucosa in giardiasis involves alterations in the microvilli and epithelial barrier dysfunction $[13,66]$. In the present study, high levels of TNF- $\alpha$ in infected untreated rats may explain the damage and inflammation of the intestinal villi together with the induction of apoptosis by G. lamblia trophozoites [67,68]. We observed significant reduction in the number of trophozoites in the groups treated with pomegranate peel extract or metronidazole, which correlates with marked recovery of the mucosal villi, reduced lymphocyte infiltration, decreased intestinal apoptotic cell death, and pronounced alleviation of the pathological changes to the villous architecture. The previous findings are in line with findings of other studies [41,42,65].

Using SEM, we clearly showed that G. lamblia trophozoites in the intestines of the infected untreated animals possess all the main features of normal trophozoites, such as the sucking disk and flagella, and they caused erosion and damage of small intestine [41,42]. Interestingly, treatment with pomegranate peel extract resulted in drastic structural changes in trophozoite structure, including damage of the sucking disk, loss of flagella, and loss of attachment to the intestinal mucosa [41,42]. These observations can be explained by the ability of the extract to damage parasite cell membrane, induce cytoplasm leakage, and parasite swelling, which, in turn, could lead to death of the parasite [42]. SEM examination of the duodenum and proximal jejunum of infected untreated rats showed features of brush border injury $[42,69,70]$. However, treatment with pomegranate peel extract resulted in marked recovery of the intestinal mucosa. All of these results indicate that pomegranate extract is effective in eradicating G. lamblia infection and protecting the intestine from G. lamblia-induced pathological damage. We believe that pomegranate extract could be a potential therapeutic option for giardiasis.

\section{Conclusions}

The development of novel drugs to control giardiasis is required because resistance to approved drugs is commonly reported. In this study, we showed that pomegranate peel ethanolic extract has marked efficacy in the treatment of giardiasis in an experimental animal model. Our findings indicate that pomegranate peel extract is effective in killing G. lamblia cysts in vitro and significantly reducing the number of cysts and trophozoites in feces and intestine, respectively. Moreover, our data showed that there was marked reduction in levels of proinflammatory cytokines that is accompanied by recovery of the intestinal epithelium and decrease in lymphocyte infiltration into the intestinal tissue. The direct cytotoxic effect of pomegranate extract and the increase in NO production in pomegranate extract-treated animals could be potential mechanisms for the therapeutic effect seen in our study. Our findings suggest that pomegranate is an effective therapeutic for giardiasis and should be considered in cases caused by G. lamblia-resistant strains.

Author Contributions: Conceptualization, A.M.E.-K., H.A.E.; experimental design and methodology, A.M.E.-K., I.A.M.A.-R., S.S.F., K.S.A., T.I., S.F.M.A., A.S.H., H.A.O., H.A.E.; writing-original drafts, A.M.E.-K., H.A.E.; data collection, A.M.E.-K., I.A.M.A.-R., S.S.F., S.F.M.A., A.S.H., H.A.O.; data analysis, A.M.E.-K., I.A.M.A.-R., K.S.A., T.I., S.S.F., S.F.M.A., A.S.H., H.A.O., H.A.E.; writing一review and editing, A.M.E.-K., K.S.A., T.I., H.A.E.; investigation, A.M.E.-K., H.A.E.; supervision, H.A.E.; project administration, H.A.E.; critical revisions and writing, H.A.E. All authors have read and agreed to the published version of the manuscript.

Funding: This research received no external funding.

Institutional Review Board Statement: The study was conducted according to the guidelines of the Declaration of Helsinki, and approved by the Research and Ethics Committee of the Faculty of Medicine, South Valley University (protocol code SVU-MED-PAR008-4).

Informed Consent Statement: Not applicable. 


\section{Data Availability Statement: Not applicable.}

Conflicts of Interest: The authors declare no conflict of interest.

\section{References}

1. Gardner, T.B.; Hill, D.R. Treatment of giardiasis. Clin. Microbiol. Rev. 2001, 14, 114-128. [CrossRef]

2. Savioli, L.; Smith, H.; Thompson, A. Giardia and Cryptosporidium join the "Neglected Diseases Initiative". Trends Parasitol. 2006, 22, 203-208. [CrossRef]

3. Lane, S.; Lloyd, D. Current trends in research into the waterborne parasite Giardia. Crit. Rev. Microbiol. 2002, 28, 123-147. [CrossRef] [PubMed]

4. Thompson, R.A. The zoonotic significance and molecular epidemiology of Giardia and giardiasis. Vet. Parasitol. 2004, 126, 15-35. [CrossRef]

5. Younas, M.; Shah, S.; Talaat, A. Frequency of Giardia lamblia infection in children with recurrent abdominal pain. J. Pak. Med. Assoc. 2008, 58, 171-174. [CrossRef] [PubMed]

6. Bayoumy, A.M.; Mohammed, K.A.; Shahat, S.A.; Ghannam, M.M.; Gazy, M.S. Role of parasites among chronic diarrheic patients. J. Egypt Soc. Parasitol. 2010, 40, 679-698.

7. Porter, J.D.; Gaffney, C.; Heymann, D.; Parkin, W. Food-borne outbreak of Giardia lamblia. Am. J. Public Health 1990, 80, 1259-1260. [CrossRef]

8. Robertson, L.J.; Forberg, T.; Gjerde, B.K. Giardia cysts in sewage influent in Bergen, Norway 15-23 months after an extensive waterborne outbreak of giardiasis. J. Appl. Microbiol. 2004, 126, 15-35. [CrossRef] [PubMed]

9. Ryu, H.; Alum, A.; Mena, K.D.; Abbaszadegan, M. Assessment of the risk of infection by Cryptosporidium and Giardia in non-potable reclaimed water. Water Sci. Technol. J. Int. Assoc. Water Pollut. Res. 2007, 55, 283-290. [CrossRef]

10. Dizdar, V.; Gilja, O.H.; Hausken, T. Increased visceral sensitivity in Giardia-induced postinfectious irritable bowel syndrome and functional dyspepsia: Effect of the 5HT3-antagonist ondansetron. Neurogastroenterol. Motil. Off. J. Eur. Gastrointest. Motil. Soc. 2007, 19, 977-982. [CrossRef] [PubMed]

11. Penrose, A.S.; Wells, E.V.; Aiello, A.E. Infectious causation of chronic disease: Examining the relationship between Giardia lamblia infection and irritable bowel syndrome. World J. Gastroenterol. 2007, 13, 4574-4578. [CrossRef] [PubMed]

12. Simsek, Z.; Zeyrek, F.; Kurcer, M.A. Effect of Giardia infection on growth and psychomotor development of children aged 0-5 years. J. Trop. Pediatr. 2004, 50, 90-93. [CrossRef]

13. Scott, K.G.; Logan, M.R.; Klammer, G.M.; Teoh, D.A.; Buret, A.G. Jejunal brush border microvillous alterations in Giardia muris-infected mice: Role of T lymphocytes and interleukin-6. Infect. Immun. 2000, 68, 3412-3418. [CrossRef] [PubMed]

14. Daniels, C.W.; Belosevic, M. Disaccharidase activity in the small intestine of susceptible and resistant mice after primary and challenge infections with Giardia muris. Am. J. Trop. Med. Hyg. 1992, 46, 382-390. [CrossRef]

15. Chin, A.C.; Teoh, D.A.; Scott, K.G.-E.; Meddings, J.B.; Macnaughton, W.K.; Buret, A.G. Strain-dependent induction of enterocyte apoptosis by Giardia lamblia disrupts epithelial barrier function in a caspase-3-dependent manner. Infect. Immun. 2002, 70, 3673-3680. [CrossRef]

16. Panaro, M.A.; Cianciulli, A.; Mitolo, V.; Mitolo, C.I.; Acquafredda, A.; Brandonisio, O.; Cavallo, P. Caspase-dependent apoptosis of the HCT-8 epithelial cell line induced by the parasite Giardia intestinalis. FEMS Immunol. Med. Microbiol. 2007, 51, 302-309. [CrossRef]

17. Roxström-Lindquist, K.; Ringqvist, E.; Palm, D.; Svärd, S. Giardia lamblia-induced changes in gene expression in differentiated Caco-2 human intestinal epithelial cells. Infect. Immun. 2005, 73, 8204-8208. [CrossRef] [PubMed]

18. Gitter, A.H.; Bendfeldt, K.; Schulzke, J.D.; Fromm, M. Leaks in the epithelial barrier caused by spontaneous and TNF-alphainduced single-cell apoptosis. FASEB J. Off. Publ. Fed. Am. Soc. Exp. Biol. 2000, 14, 1749-1753. [CrossRef]

19. Hill, D.R. Giardiasis: Issues in diagnosis and management. Infect. Dis. Clin. N. Am. 1993, 7, 503-525. [CrossRef]

20. Beyhan, Y.E.; Hökelek, M. Giardia muris infection in laboratory rats (Rattus norvegicus) and treatment with metronidazole. Turkiye Parazitolojii Dergisi 2014, 38, 181-184. [CrossRef]

21. Lau, A.H.; Lam, N.P.; Piscitelli, S.C.; Wilkes, L.; Danziger, L.H. Clinical pharmacokinetics of metronidazole and other nitroimidazole anti-infectives. Clin. Pharmacokinet. 1992, 23, 328-364. [CrossRef]

22. Leitsch, D. Drug Resistance in the Microaerophilic Parasite Giardia lamblia. Curr. Trop. Med. Rep. 2015, 2, 128-135. [CrossRef] [PubMed]

23. Kusumi, R.K.; Plouffe, J.F.; Wyatt, R.H.; Fass, R.J. Central nervous system toxicity associated with metronidazole therapy. Ann. Intern. Med. 1980, 93, 59-60. [CrossRef]

24. Levi, G.C.; de Avila, C.A.; Amato Neto, V. Efficacy of various drugs for treatment of giardiasis: A comparative study. Am. J. Trop. Med. Hyg. 1977, 26, 564-565. [CrossRef] [PubMed]

25. Rustia, M.; Shubik, P. Experimental induction of hepatomas, mammary tumors, and other tumors with metronidazole in noninbred Sas:MRC(WI)BR rats. J. Natl. Cancer Inst. 1979, 63, 863-868. [CrossRef]

26. Rustia, M.; Shubik, P. Induction of lung tumors and malignant lymphomas in mice by metronidazole. J. Natl. Cancer Inst. 1972, $48,721-729$.

27. Golami, S.; Rahimi-Esboei, B.; Mousavi, P.; Marhaba, Z.; Youssefi, M.R.; Rahimi, M.T. Survey on efficacy of chloroformic extract of Artemisia annua against Giardia lamblia trophozoite and cyst in vitro. J. Parasit. Dis. 2016, 40, 88-92. [CrossRef] 
28. Abdel Moneim, A.E. Evaluating the potential role of pomegranate peel in aluminum-induced oxidative stress and histopathological alterations in brain of female rats. Biol. Trace Elem. Res. 2012, 150, 328-336. [CrossRef]

29. Reddy, M.K.; Gupta, S.K.; Jacob, M.R.; Khan, S.I.; Ferreira, D. Antioxidant, antimalarial and antimicrobial activities of tannin-rich fractions, ellagitannins and phenolic acids from Punica granatum L. Planta Med. 2007, 73, 461-467. [CrossRef]

30. Foss, S.R.; Nakamura, C.V.; Ueda-Nakamura, T.; Cortez, D.A.G.; Endo, E.H.; Dias Filho, B.P. Antifungal activity of pomegranate peel extract and isolated compound punicalagin against dermatophytes. Ann. Clin. Microbiol. Antimicrob. 2014, 13, 32. [CrossRef]

31. Al-Mathal, E.M.; Alsalem, A.M. Pomegranate (Punica granatum) peel is effective in a murine model of experimental Cryptosporidium parvum. Exp. Parasitol. 2012, 131, 350-357. [CrossRef]

32. Al-Megrin, W.A.I. Efficacy of pomegranate (Punica granatum) peel extract against Hymenolepis nana in infections mice. Biosci. Biotechnol. Res. Asia 2016, 13, 103-108. [CrossRef]

33. Calzada, F.; Yépez-Mulia, L.; Aguilar, A. In vitro susceptibility of Entamoeba histolytica and Giardia lamblia to plants used in Mexican traditional medicine for the treatment of gastrointestinal disorders. J. Ethnopharmacol. 2006, 108, 367-370. [CrossRef]

34. Dell'Agli, M.; Galli, G.V.; Corbett, Y.; Taramelli, D.; Lucantoni, L.; Habluetzel, A.; Maschi, O.; Caruso, D.; Giavarini, F.; Romeo, S.; et al. Antiplasmodial activity of Punica granatum L. fruit rind. J. Ethnopharmacol. 2009, 125, 279-285. [CrossRef]

35. Fernandes, P.; Assreuy, J. Role of nitric oxide and superoxide in Giardia lamblia killing. Braz. J. Med. Biol. Res. 1997, 30, 93-99. [CrossRef] [PubMed]

36. Fernandes, R.M.; Rodrigues, M.D.L.D.A.; Borba, H.R.; Fernandes, M.Z.D.L.C.M.; De Amorim, A. Ausencia da atividade antihelmintica de plantas em frangos de corte naturalmente infectados com Heterakis gallinarum (Schranck, 1788) Madsen, 1949. Ciencia Rural 2004, 34, 1629-1632. [CrossRef]

37. Castagna, F.; Britti, D.; Oliverio, M.; Bosco, A.; Bonacci, S.; Iriti, G.; Ragusa, M.; Musolino, V.; Rinaldi, L.; Palma, E.; et al. In Vitro Anthelminthic Efficacy of Aqueous Pomegranate (Punica granatum L.) Extracts against Gastrointestinal Nematodes of Sheep. Pathogens 2020, 9, 1063. [CrossRef]

38. Brandelli, C.L.C.; Giordani, R.B.; De Carli, G.A.; Tasca, T. Indigenous traditional medicine: In vitro anti-giardial activity of plants used in the treatment of diarrhea. Parasitol. Res. 2009, 104, 1345-1349. [CrossRef]

39. Al-Kaissi, I.N. The effect of Aqueous some plants Extract on Giardia lamblia in vitro. Al-Anbar J. Vet. Sci. 2010, 3, 1-58.

40. Rahimi-Esboei, B.; Ebrahimzadeh, M.A.; Gholami, S.; Falah-Omrani, V. Anti-giardial activity of Sambucus ebulus. Eur. Rev. Med. Pharmacol. Sci. 2013, 17, 2047-2050.

41. Abdalla, S.F.; Ramadan, N.I.; Mohamed, A.A.; El-Deeb, H.K.; Al-Khadrawy, F.M.; Badawy, A.F. A study on the effect of Myrtus communis and Olibanum on Giardia lamblia infection in Egypt. Parasitol. United J. 2011, 4, 89-100.

42. Oyetayo, O.; Adetuyi, F.C.; Akinyosoye, F.A. Safety and protective effect of Lactobacillus acidophilus and Lactobacillus casei used as probiotic agent in vivo. Afr. J. Biotechnol. 2003, 2, 448-452. [CrossRef]

43. Rayan, P.; Stenzel, D.; McDonnell, P.A. The effects of saturated fatty acids on Giardia duodenalis trophozoites in vitro. Parasitol. Res. 2005, 97, 191-200. [CrossRef]

44. Zhou, P.; Li, E.; Shea-Donohue, T.; Singer, S.M. Tumour necrosis factor alpha contributes to protection against Giardia lamblia infection in mice. Parasite Immunol. 2007, 29, 367-374. [CrossRef] [PubMed]

45. Liu, P.-F.; Hu, Y.-C.; Kang, B.-H.; Tseng, Y.-K.; Wu, P.-C.; Liang, C.-C.; Hou, Y.-Y.; Fu, T.-Y.; Liou, H.-H.; Hsieh, I.-C.; et al. Expression levels of cleaved caspase- 3 and caspase-3 in tumorigenesis and prognosis of oral tongue squamous cell carcinoma. PLoS ONE 2017, 12, e0180620. [CrossRef]

46. Hayat, M. Principles and Technique of Electron Microscopy, 2nd ed.; University Park Press: New Jersey, NJ, USA, 1981 ; Volume 1.

47. Tanaka, T.; Nonaka, G.; Nishioka, I. Tannins and Related Compounds. C.: Reaction of Dehydrohexahydroxydiphenic Acid Esters with Bases, and Its Application to the Structure Determination of Pomegranate Tannins, Granatins A and B. Chem. Pharm. Bull. 1990, 38, 2424-2428. [CrossRef]

48. Amakura, Y.; Okada, M.; Tsuji, S.; Tonogai, Y. High-performance liquid chromatographic determination with photodiode array detection of ellagic acid in fresh and processed fruits. J. Chromatogr. A 2000, 896, 87-93. [CrossRef]

49. Satomi, H.; Umemura, K.; Ueno, A.; Hatano, T.; Okuda, T.; Noro, T. Carbonic anhydrase inhibitors from the pericarps of Punica granatum L. Biol. Pharm. Bull. 1993, 16, 787-790. [CrossRef]

50. Lansky, E.P.; Newman, R.A. Punica granatum (pomegranate) and its potential for prevention and treatment of inflammation and cancer. J. Ethnopharmacol. 2007, 109, 177-206. [CrossRef]

51. Plumb, G.W.; de Pascual-Teresa, S.; Santos-Buelga, C.; Rivas-Gonzalo, J.C.; Williamson, G. Antioxidant properties of gallocatechin and prodelphinidins from pomegranate peel. Redox Rep. 2002, 7, 41-46. [CrossRef]

52. Li, E.; Zhou, P.; Singer, S.M. Neuronal nitric oxide synthase is necessary for elimination of Giardia lamblia infections in mice. J. Immunol. 2006, 176, 516-521. [CrossRef] [PubMed]

53. Liew, F.Y.; Wei, X.Q.; Proudfoot, L. Cytokines and nitric oxide as effector molecules against parasitic infections. Philos. Trans. R. Soc. Lond. Ser. B Biol. Sci. 1997, 352, 1311-1315. [CrossRef]

54. Brown, D.M.; Upcroft, J.A.; Edwards, M.R.; Upcroft, P. Anaerobic bacterial metabolism in the ancient eukaryote Giardia duodenalis. Int. J. Parasitol. 1998, 28, 149-164. [CrossRef]

55. Maloney, J.; Keselman, A.; Li, E.; Singer, S.M. Macrophages expressing arginase 1 and nitric oxide synthase 2 accumulate in the small intestine during Giardia lamblia infection. Microbes Infect. 2015, 17, 462-467. [CrossRef] [PubMed] 
56. Stadelmann, B.; Hanevik, K.; Andersson, M.K.; Bruserud, O.; Svärd, S.G. The role of arginine and arginine-metabolizing enzymes during Giardia-Host cell interactions in vitro. BMC Microbiol. 2013, 13, 256. [CrossRef]

57. He, Q.; Leitch, G.J.; Visvesvara, G.S.; Wallace, S. Effects of nifedipine, metronidazole, and nitric oxide donors on spore germination and cell culture infection of the microsporidia Encephalitozoon hellem and Encephalitozoon intestinalis. Antimicrob. Agents Chemother. 1996, 40, 179-185. [CrossRef]

58. Wink, D.A.; Miranda, K.M.; Espey, M.G. Effects of oxidative and nitrosative stress in cytotoxicity. Semin. Perinatol. 2000, 24, 20-23. [CrossRef]

59. Zhou, P.; Li, E.; Zhu, N.; Robertson, J.; Nash, T.; Singer, S.M. Role of interleukin-6 in the control of acute and chronic Giardia lamblia infections in mice. Infect. Immun. 2003, 71, 1566-1568. [CrossRef]

60. Matowicka-Karna, J.; Dymicka-Piekarska, V.; Kemona, H. IFN-gamma, IL-5, IL-6 and IgE in patients infected with Giardia intestinalis. Folia Histochem. Cytobiol. 2009, 47, 93-97. [CrossRef]

61. Kamda, J.D.; Singer, S.M. Phosphoinositide 3-kinase-dependent inhibition of dendritic cell interleukin-12 production by Giardia lamblia. Infect. Immun. 2009, 77, 685-693. [CrossRef] [PubMed]

62. Bienz, M.; Dai, W.J.; Welle, M.; Gottstein, B.; Müller, N. Interleukin-6-deficient mice are highly susceptible to Giardia lamblia infection but exhibit normal intestinal immunoglobulin A responses against the parasite. Infect. Immun. 2003, 71, 1569-1573. [CrossRef] [PubMed]

63. Kuhn, K.A.; Manieri, N.A.; Liu, T.-C.; Stappenbeck, T.S. IL-6 stimulates intestinal epithelial proliferation and repair after injury. PLoS ONE 2014, 9, e114195. [CrossRef] [PubMed]

64. Rietdijk, S.T.; D'Haens, G.R. Recent developments in the treatment of inflammatory bowel disease. J. Dig. Dis. 2013, 14, 282-287. [CrossRef]

65. Abdel-Fattah, N.S.; Nada, O.H. Effect of propolis versus metronidazole and their combined use in treatment of acute experimental giardiasis. J. Egypt Soc. Parasitol. 2007, 37, 691-710.

66. Slee, E.A.; Harte, M.T.; Kluck, R.M.; Wolf, B.B.; Casiano, C.A.; Newmeyer, D.D.; Wang, H.G.; Reed, J.C.; Nicholson, D.W.; Alnemri, E.S.; et al. Ordering the cytochrome c-initiated caspase cascade: Hierarchical activation of caspases-2, -3, -6, -7, -8, and -10 in a caspase-9-dependent manner. J. Cell Biol. 1999, 144, 281-292. [CrossRef]

67. Podolsky, D.K. Inflammatory bowel disease. N. Engl. J. Med. 2002, 347, 417-429. [CrossRef]

68. Rogler, G.; Andus, T. Cytokines in inflammatory bowel disease. World J. Surg. 1998, 22, 382-389. [CrossRef]

69. Khanna, R.; Joshi, K.; Kum, K.; Malik, A.K.; Vinayak, V.K. An ultrastructural analysis of changes in surface architecture of intestinal mucosa following Giardia lamblia infection in mice. Gastroenterol. Jpn. 1990, 25, 649-658. [CrossRef] [PubMed]

70. Buret, A.; Gall, D.G.; Olson, M.E. Effects of murine giardiasis on growth, intestinal morphology, and disaccharidase activity. J. Parasitol. 1990, 76, 403-409. [CrossRef] [PubMed] 